\title{
Reducing Conservatism in Aircraft Engine Response Using Conditionally Active Min-Max Limit Regulators
}

Ryan D. May

ASRC Aerospace Corporation, Cleveland, Ohio

Sanjay Garg

Glenn Research Center, Cleveland, Ohio 


\section{NASA STI Program . . . in Profile}

Since its founding, NASA has been dedicated to the advancement of aeronautics and space science. The NASA Scientific and Technical Information (STI) program plays a key part in helping NASA maintain this important role.

The NASA STI Program operates under the auspices of the Agency Chief Information Officer. It collects, organizes, provides for archiving, and disseminates NASA's STI. The NASA STI program provides access to the NASA Aeronautics and Space Database and its public interface, the NASA Technical Reports Server, thus providing one of the largest collections of aeronautical and space science STI in the world. Results are published in both non-NASA channels and by NASA in the NASA STI Report Series, which includes the following report types:

- TECHNICAL PUBLICATION. Reports of completed research or a major significant phase of research that present the results of NASA programs and include extensive data or theoretical analysis. Includes compilations of significant scientific and technical data and information deemed to be of continuing reference value. NASA counterpart of peer-reviewed formal professional papers but has less stringent limitations on manuscript length and extent of graphic presentations.

- TECHNICAL MEMORANDUM. Scientific and technical findings that are preliminary or of specialized interest, e.g., quick release reports, working papers, and bibliographies that contain minimal annotation. Does not contain extensive analysis.

- CONTRACTOR REPORT. Scientific and technical findings by NASA-sponsored contractors and grantees.
- CONFERENCE PUBLICATION. Collected papers from scientific and technical conferences, symposia, seminars, or other meetings sponsored or cosponsored by NASA.

- SPECIAL PUBLICATION. Scientific, technical, or historical information from NASA programs, projects, and missions, often concerned with subjects having substantial public interest.

- TECHNICAL TRANSLATION. Englishlanguage translations of foreign scientific and technical material pertinent to NASA's mission.

Specialized services also include creating custom thesauri, building customized databases, organizing and publishing research results.

For more information about the NASA STI program, see the following:

- Access the NASA STI program home page at http://www.sti.nasa.gov

- E-mail your question to help@sti.nasa.gov

- Fax your question to the NASA STI Information Desk at 443-757-5803

- Phone the NASA STI Information Desk at 443-757-5802

- Write to: STI Information Desk NASA Center for AeroSpace Information 7115 Standard Drive Hanover, MD 21076-1320 


\section{Reducing Conservatism in Aircraft Engine Response Using Conditionally Active Min-Max Limit Regulators}

Ryan D. May

ASRC Aerospace Corporation, Cleveland, Ohio

Sanjay Garg

Glenn Research Center, Cleveland, Ohio

Prepared for the

Turbo Expo 2012

sponsored by the American Society of Mechanical Engineers (ASME)

Copenhagen, Denmark, June 11-15, 2012

National Aeronautics and

Space Administration

Glenn Research Center

Cleveland, Ohio 44135 
Trade names and trademarks are used in this report for identification only. Their usage does not constitute an official endorsement, either expressed or implied, by the National Aeronautics and Space Administration.

Level of Review: This material has been technically reviewed by technical management.

Available from

NASA Center for Aerospace Information 7115 Standard Drive

Hanover, MD 21076-1320
National Technical Information Service 5301 Shawnee Road Alexandria, VA 22312

Available electronically at http://www.sti.nasa.gov 


\title{
Reducing Conservatism in Aircraft Engine Response Using Conditionally Active Min-Max Limit Regulators
}

\author{
Ryan D. May \\ ASRC Aerospace Corporation \\ Cleveland, Ohio 44135 \\ Sanjay Garg \\ National Aeronautics and Space Administration \\ Glenn Research Center \\ Cleveland, Ohio 44135
}

\begin{abstract}
Current aircraft engine control logic uses a Min-Max control selection structure to prevent the engine from exceeding any safety or operational limits during transients due to throttle commands. This structure is inherently conservative and produces transient responses that are slower than necessary. In order to utilize the existing safety margins more effectively, a modification to this architecture is proposed, referred to as a Conditionally Active (CA) limit regulator. This concept uses the existing Min-Max architecture with the modification that limit regulators are active only when the operating point is close to a particular limit. This paper explores the use of CA limit regulators using a publicly available commercial aircraft engine simulation. The improvement in thrust response while maintaining all necessary safety limits is demonstrated in a number of cases.
\end{abstract}

\section{Introduction}

The control system in modern commercial aircraft engines is designed to operate the engine in a safe manner throughout its operating envelope during its on-wing life. This challenging objective is typically achieved through the use of a Min-Max architecture (Refs. 1 and 2) as shown in Figure 1. Each of the physical and operational engine limits of concern has a unique regulator associated with it. Each of these regulators generates a desired fuel flow rate $(W f)$ that will maintain the limit. The throttle is used as input to either an engine pressure ratio (EPR) setpoint regulator or a fan speed (Nf) setpoint regulator. The desired fuel flow from the setpoint regulator and each of the maximum limit regulators are input to a minimum selector. The output of this Min selector and each of the minimum limit regulator outputs are input to a maximum selector. Thus, the output from the Min-Max selector is the fuel flow rate command that ensures that none of the operational and safety limits will be violated.

This architecture, which is typical for today's commercial aircraft engine controllers, is inherently conservative. The engine limit regulators are typically designed as simple regulators (e.g., Proportional-Integral controllers) and they are each independently designed. The Min-Max architecture then ensures that the most conservative control input is chosen. A limit regulator can become active even when there is no immediate danger of reaching the limit. This results in a slower engine response than is actually necessary to maintain safe operation. Typically, this has not been a problem as this conservative design is still able to meet the FAA certification requirements for engine response time. However, in emergencies, such as the Sioux City crash of United flight 232 in 1989, this conservative design may prevent the engine from achieving the faster response times that might be needed to provide adequate flight control (Ref. 3).

Previous research (Ref. 4) on developing methods to enhance the engine response for emergency control has shown that this conservative limit protection approach prevents the engine from delivering the dynamic response that is actually achievable. The authors of Reference 4 were attempting to achieve faster engine response by increasing the bandwidth of the setpoint controller, using a 90,000 lbf engine simulation as the application. However, they found that the turbine temperature limit would activate and slow the engine response. It was discovered that the temperature limit regulator was becoming active even when the actual temperature was far from its limit. It is worth noting that while a turbine temperature limit is not typically found in commercial aircraft engine controller, it is possible that other limits become active prematurely and unnecessarily slow the engine response.

More recent research has studied means of avoiding this problem by the use of alternative limit protection architectures. One recent study investigates the use of Sliding Mode controllers as a means of preventing unnecessary limiter interventions while ensuring safe performance Reference 5 . Another recent study investigates the use of a reference governor on a linearized engine model Reference 6. However, the changes proposed in these studies necessitate a complete redesign of the engine controller which will impose challenges in terms of verification across the whole operating envelope and acceptance by engine control implementers.

In an effort to maintain the current control architecture while reducing this conservatism, a new scheme is proposed wherein the engine control limit regulators become active only when the variable to be limited is within a specified close 


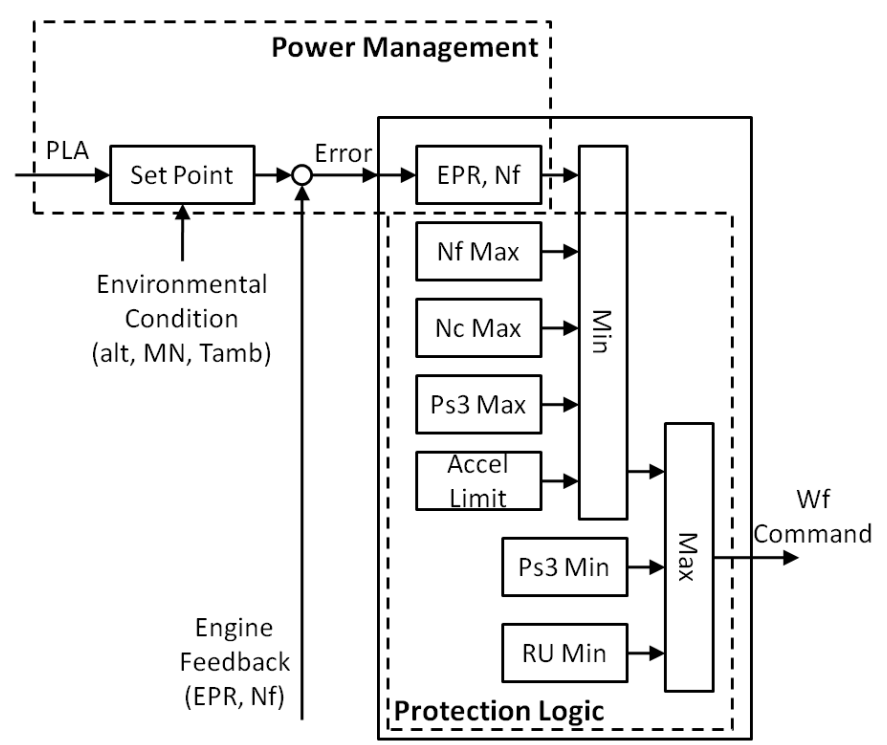

Figure 1.-Diagram of the C-MAPSS40k engine control system with throttle (PLA) input and Wf command output. The Power Management and Protection Logic subsystems are highlighted.

bound of the actual limit value. This paper first presents the formulation of this CA limit regulator protection scheme. Choosing appropriate bounds for when the limit regulator becomes active is then discussed in the context of application to an engine simulation. Various aspects of engine operation with the baseline Min-Max limit protection and the enhanced CA limit protection are evaluated and compared. Conclusions from this study and areas that need further investigation are then summarized.

\section{Nomenclature}

$\alpha$

$\beta$

CA

C-MAPSS40k

e

EPR

$F_{\text {net }}$

$\gamma$

ISA

HPC

NC

$\begin{array}{ll}\text { Nf } & \text { Fan Shaft Speed [rpm] } \\ \text { PLA } & \text { Power Lever Angle [deg] } \\ \text { Ps3 } & \text { Combustor Entrance Static Pressure [psi] } \\ \text { RU } & \text { Ratio Unit (Wf/Ps3) [lbm/s/psi] } \\ \text { SLS } & \text { Sea-level static flight condition (0 ft altitude, } \\ & \text { Mach 0.0, ISA+0 degrees) } \\ \text { SM } & \text { Surge Margin [\%] } \\ \Delta T & \text { Controller step size [s] } \\ W f & \text { Fuel Flow Rate [lbm/s] } \\ y & \text { The measured value of a limited engine parameter } \\ y_{\max } & \text { The maximum limit of the engine parameter } y \\ y_{\min } & \text { The minimum limit of the engine parameter } y\end{array}$

\section{Conditionally Active Limit Regulation}

Consider the generic form of a Min-Max control selection scheme as shown in Figure 2. Here, $z$ is the regulated variable of interest to provide desired performance, i.e., fan speed or EPR in the case of an aircraft gas turbine engine. Output $y_{1}$ is to be maintained below a certain maximum value $\left(y_{1 \max }\right)$ and output $y_{2}$ is to be maintained above a certain minimum value $\left(y_{2 \min }\right)$. For simplicity, $y_{1}$ and $y_{2}$ are the only limits considered, however the premise extends to an arbitrary number of output variables.

In the above Min-Max selection scheme, the limit regulated outputs are constantly being used in the selection of the commanded input, $u$, to the plant. However, such an approach is inherently conservative in that the commanded input might be limited by one of the limit regulators even if the value of the output to be limited is far from its limit.

Since the purpose of the limit regulator is to ensure that the specified limit is not violated, it does not need to be active if there is no chance of the limit being reached. The idea behind CA limit regulators is to make the limit regulator active in the Min-Max selection scheme only when there is a reasonable chance that the limit will be reached if the input command generated by the setpoint regulator (or another limit regulator) is not modified.

An operational region for a limit regulator to be active in the Min-Max selection scheme can then be defined as: Condition 1: the variable to be limited is "close" to its limit value, and Condition 2: its current rate is such that it will reach the limit within a certain period of time with no other changes. In order for the limit regulator to be active, both Conditions 1 and 2 must be true.

For the case of a maximum limit variable, $y_{1}$, the objective will be to keep $y_{1} \leq y_{1 \max }$. Condition 1 can then be stated as:

$$
y_{1} \geq\left(1-\alpha_{1}\right) * y_{1 \max }
$$

where $\alpha_{1}$ is a design parameter that is non-negative. 


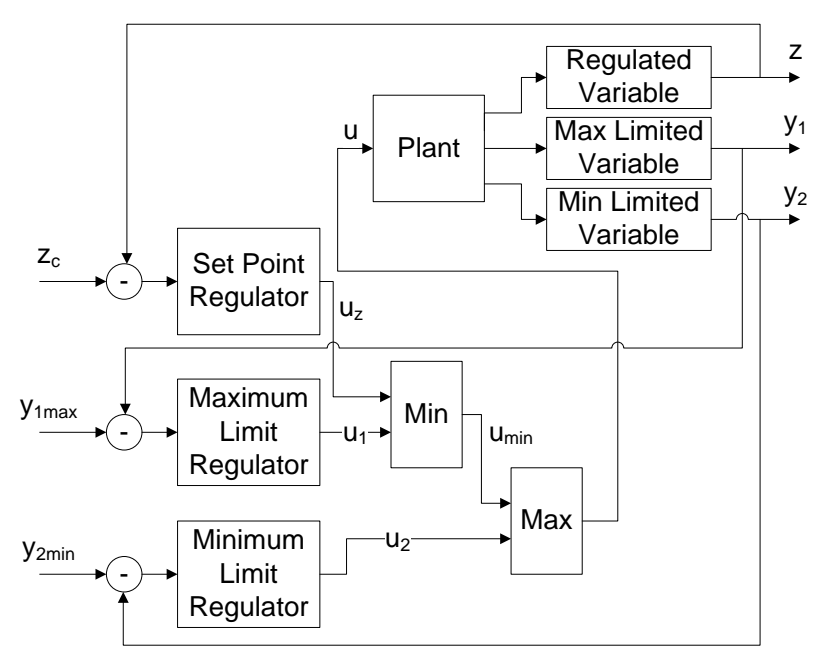

Figure 2.-A generic Min-Max scheme used to select the input to a plant such that the regulated variable, $\mathrm{z}$, tracks $\mathrm{z}_{\mathrm{c}}$ with the constraints that $y_{1}$ does not exceed y1max and $y_{2}$ does not fall below $y_{2} \min$.

For condition 2, consider the controller update time to be $\Delta T$ with the objective to activate the limit regulator if the current rate of change of $y_{1}$ is such that it will reach $y_{1 \max }$ in $\beta_{1}$ time steps. The condition can be stated as

$$
y_{1}+\frac{d}{d t} y_{1} * \beta_{1} * \Delta T \geq y_{1 \max }
$$

where $\beta_{1}$ is a design parameter that is non-negative.

An example maximum limited output variable trajectory is shown in Figure 3. The output, $y_{1}$, is initially below the limit and both Equations (1) and (2) are false. At time $t_{\mathrm{A}}, y_{1}$ crosses into the region for which Equation (1) is true-it is "close" to the limit. However, the slope at point $\mathrm{A}$ is too low to intersect $y_{1 \max }$ within $\beta_{1}$ time steps $\left(t_{\mathrm{A}}{ }^{\prime}>t_{\mathrm{A}}+\beta_{1} * \Delta T\right)$. At all points between $\mathrm{A}$ and $\mathrm{B}$ the slope still does not exceed the necessary threshold. Visually, it does not appear that the trajectory will violate the limit. However at point $B$ there is a sudden upswing and now Equation (2) is validated $\left(t_{\mathrm{B}}{ }^{\prime}<t_{\mathrm{B}}+\beta_{1}{ }^{*} \Delta T\right)$ thus the CA limit regulator would become active and act to restrict the input to prevent $y_{1}$ from exceeding $y_{1 \text { max }}$.

For the case of a minimum limit variable, $y_{2}$, the objective will be to keep $y_{2} \geq y_{2 \mathrm{~min}}$. Conditions 1 and 2 can be developed into equations analogous to Equations (1) and (2) with non-negative design parameters $\alpha_{2}$ and $\beta_{2}$.

$$
\begin{gathered}
y_{2} \leq\left(1+\alpha_{2}\right) * y_{2 \min } \\
y_{2}+\frac{d}{d t} y_{2} * \beta_{2} * \Delta T \leq y_{2 \min }
\end{gathered}
$$

It is worth noting that when Condition 1 is met (the variable is "close" to the limit) that the construction of Condition 2 can

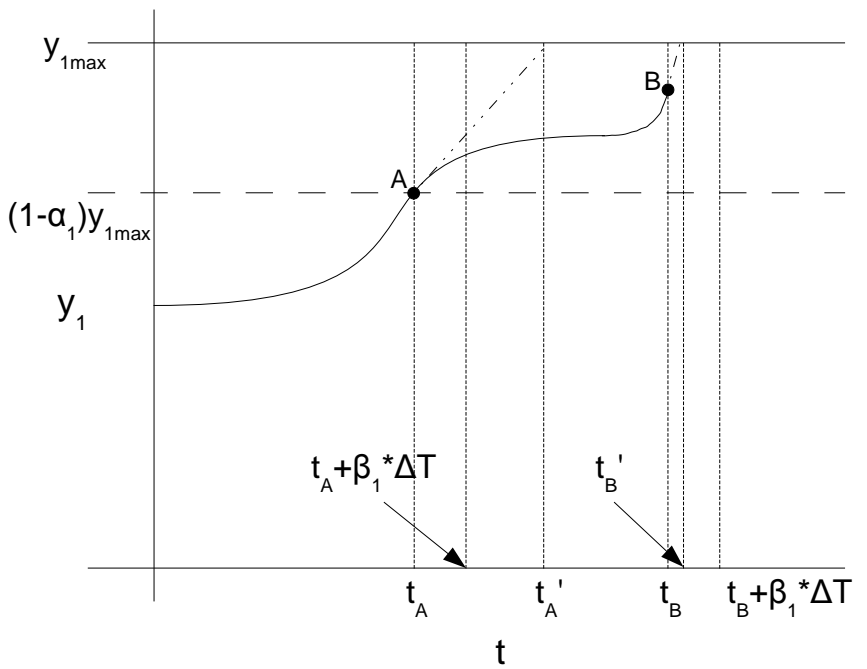

Figure 3.-Plot showing an example $y_{1}(\mathrm{t})$ for which Equation (1) is satisfied starting at $t_{\mathrm{A}}$, but Equation (2) isn't satisfied until $t_{\mathrm{B}}$. Therefore, the CA limit regulator would not become active until time $t_{\mathrm{B}}$.

cause the limit regulator to switch between active and inactive. This behavior could result in chatter in the fuel flow command. If this chatter is found to occur and negatively impact the performance, an additional condition could be imposed such as $y_{1} \geq\left(1-\gamma_{1}\right) * y_{1 \max }$ where $\gamma_{1}$ is a nonnegative number that is less than $\alpha_{1}$. This condition would be included into the CA activation logic through the following Boolean expression: (Conditions 1 and 2) or Condition 3. However, this condition is not implemented in this study.

Defining the maximum limit regulator error as $e_{1}=y_{1 \max }-y_{1}$, Equations (1) and (2) can be written as:

$$
\begin{aligned}
& e_{1} \leq \alpha_{1} * y_{1 \max } \\
& \frac{d}{d t} e_{1} \leq \frac{-e_{1}}{\beta_{1} * \Delta T}
\end{aligned}
$$

With the minimum limit regulator error defined as $e_{2}=y_{2 \min }-y_{2}$, Equations (3) and (4) can be stated as:

$$
\begin{aligned}
& e_{2} \geq-\alpha_{2} * y_{2 \min } \\
& \frac{d}{d t} e_{2} \geq \frac{-e_{2}}{\beta_{2} * \Delta T}
\end{aligned}
$$

When implemented in the generic Min-Max selector block diagram of Figure 2, the above implementation of the CA limit regulator architecture is shown in Figure 4. The switches shown on the output of each limit regulator only connect to the Max and Min selector blocks when both bounding conditions are true-Equations (5) and (6) for the Max limit regulator and Equations (7) and (8) for the Min limit regulator. The rest of the system shown in Figure 2 remains unchanged. 


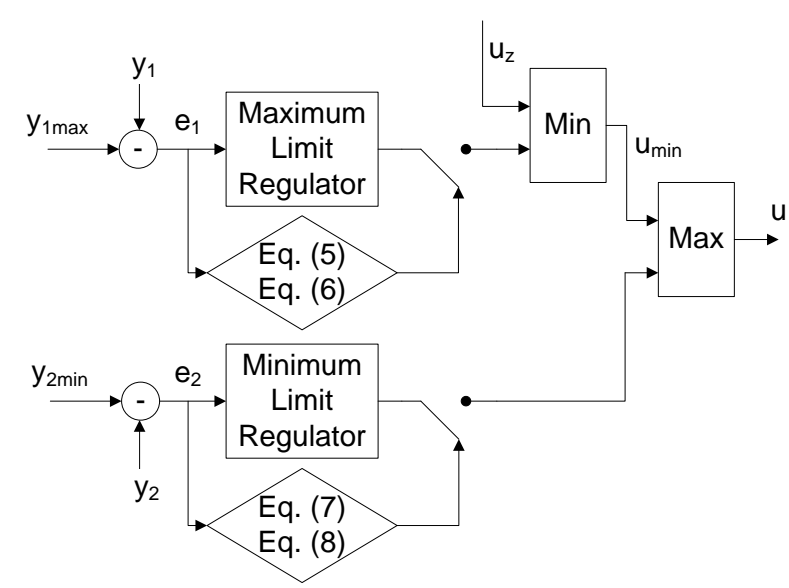

Figure 4.- -The generic Min-Max selection scheme modified to include conditionally active limit regulators. When both of the necessary conditions are true, the regulator output is passed to the Min or Max selector block.

As most control laws are implemented in a digital processor, it is necessary to develop discrete-time versions of these equations. The discrete version of the maximum limit inequalities Equations (5) and (6) is listed below where $e[k]$ refers to the error at the current time index and $e[k-1]$ to the error at the previous time step.

$$
\begin{gathered}
e_{1}[k] \leq \alpha^{*} y_{1 \max } \\
\frac{1}{\Delta T}\left(e_{1}[k]-e_{1}[k-1]\right) \leq \frac{-e_{1}[k]}{\beta_{1} * \Delta T}
\end{gathered}
$$

Also, the designer may find it desirable to use a filtered version of $e[k]$ to reduce noise. For the case of a minimum limit, discrete time equations can be developed in a similar manner.

The designer is thus given two parameters which adjust the size of the region in which the limiter will be active. For parameters which change value quickly a large $\alpha$ and/or $\beta$ may be needed to allow the limit regulator to become active early enough to arrest the behavior.

Currently, the authors have not devised an analytical approach to determine $\alpha$ and $\beta$ for an arbitrary limit regulator. However, the next section contains an empirical study that was done to choose the CA parameters for a particular engine simulation. Until an analytical methodology is found, this empirical approach should allow for the implementation of CA limit regulators in other engines.

\section{Empirical Method for Choosing Conditional Bounds}

Empirically tuning the conditional bounds, $\alpha$ and $\beta$, will be done one at a time. The derivative term will be disabled and a suitable proportional gain chosen. The choice of $\alpha$ will be made by selecting a value as small as possible that produces a "safe" outcome in the worst-case situation. The derivative term will then be tested at various values and the smallest value that produces a safe transient will be selected.

The engine simulation used for the remainder of this work is the publicly-available Commercial Modular Aero-Propulsion System Simulation 40,000 lbf (C-MAPSS40k) developed by NASA Reference 7. This is a simulation of a generic highbypass, twin-spool, commercial aircraft engine in the 40,000 lbf thrust class. The simulation includes a realistic baseline engine controller Reference 1 against which to compare the performance with the CA limit regulators. The use of this realistic controller allows for any arbitrary throttle transient to be simulated. Additionally, it has realistic surge margin models that include the impact of engine deterioration, changes in compressor tip clearance, and heat transfer between the compressor and the casing. C-MAPSS40k also allows for studying the effects of engine degradation through implementation of a set of adjustable health parameters representing performance deterioration within each of the major rotating engine components. The simulation is constructed to allow the user to choose EPR or fan speed ( Nf) as the main regulated variable to command thrust changes through the throttle. For the purposes of this study, EPR will be used as the main regulated variable.

The Min-Max architecture used in C-MAPSS40k is shown in Figure 1. The maximum limit regulators used are: "Nf Max," "Nc Max," "Ps3 Max," and "Accel Limit," while the two minimum limit regulators are "Ps3 Min" and "RU Min." Many of these are straightforward: the fan speed and core speed maximum limiters are to prevent over-speed conditions on the two shafts; the Ps3 maximum limit prevents combustor overpressurization; the ratio unit (RU), fuel flow rate divided by Ps3, minimum limit is used to ensure that lean blow-out conditions do not occur and to prevent Low Pressure Compressor surge. The Ps3 minimum limit is used to set the idle operating limit. The maximum acceleration limit and the minimum ratio unit limit are designed to ensure safe engine operation during transients, specifically to preserve compressor surge margin. During engine acceleration, the High Pressure Compressor (HPC) is likely to surge, and the acceleration limit regulator is designed to prevent HPC surge. During engine deceleration, the Low Pressure Compressor (LPC) is more likely to surge and the RU limit regulator is designed to prevent LPC surge.

Currently, there is no feasible means of sensing the compressor surge margin on an operating engine. Thus the acceleration limiter must limit a sensed value that serves as a stand-in for surge margin. There are many different ways to do this Reference 8. In C-MAPSS40k, the acceleration limiter is applied to maintain HPC surge margin. It is implemented by limiting the core shaft acceleration based on the current core shaft speed. The higher the shaft speed, the higher the allowed acceleration. For LPC surge margin, the ratio unit is used as a stand-in. Thus the RU limit regulator ensures that a minimum Wf/Ps3 is maintained at all time in order to preserve LPC surge margin. 
These particular limits were chosen for the C-MAPSS40k controller, but are by no means the only limits which are capable of ensuring safe engine operation. For a full discussion on the various limiter choices, see Reference 2 .

The process for choosing the bounds for the CA limit regulators will be demonstrated for the acceleration limiter and then repeated for the rest of the limiters. The purpose of the acceleration limiter is to prevent HPC surge. The distance from surge is measured by surge margin (SM) where a value of zero means that a surge has occurred. In C-MAPSS40k, an HPC surge is most likely to occur on a fully deteriorated engine during a full throttle burst.

An initial look at the engine behavior using the baseline control law is useful for further understanding the need for conditionally active limit regulators. Plotted in Figure 5 are the EPR and net engine thrust $\left(F_{n e t}\right)$ for an idle to full throttle transient which starts at $15 \mathrm{~s}$. The engine is fully degraded (i.e., the health parameters in the simulation are chosen to correspond to an engine at the end of its useful life-worstcase scenario) and operating at sea-level static (SLS) flight conditions. Figure 5 shows a long delay between the EPR command and the response of the engine with baseline control. This long delay manifests as a slow response in engine thrust.

In order to understand the reason for the long delay we look at the state of the acceleration limit regulator (as shown in Fig. 6) during the transient. A value of one indicates that the limit regulator is active and overriding the EPR setpoint controller fuel flow rate command in order to preserve HPC surge margin. It can be seen that the limit regulator is active for more than $2 \mathrm{~s}$ almost immediately following the start of the transient.

The question is, does the acceleration limit regulator need to be active for this period of time? To answer that, the core shaft acceleration, which is limited by the acceleration limit, and HPC surge margin are plotted in Figure 7. The top plot shows the acceleration limit, which for C-MAPSS40k is a limit on $d N c / d t$ based on the current core shaft speed, $N c$, which is represented by the dotted line, as well as the actual $d N c / d t$ versus $N c$ is shown (solid line). The conservative nature of the baseline limit regulator can be seen from the significant difference between the limit and actual value of the core acceleration. Further, when the HPC surge margin is examined, there is a significant amount of transient surge margin (12 percent) available. Thus, the acceleration limit regulator does not need to be active for as long as it is, meaning that the transient thrust response is being slowed because of unneeded activation of the acceleration limit regulator. To improve the response we can use an appropriately tuned conditionally active limit regulator.
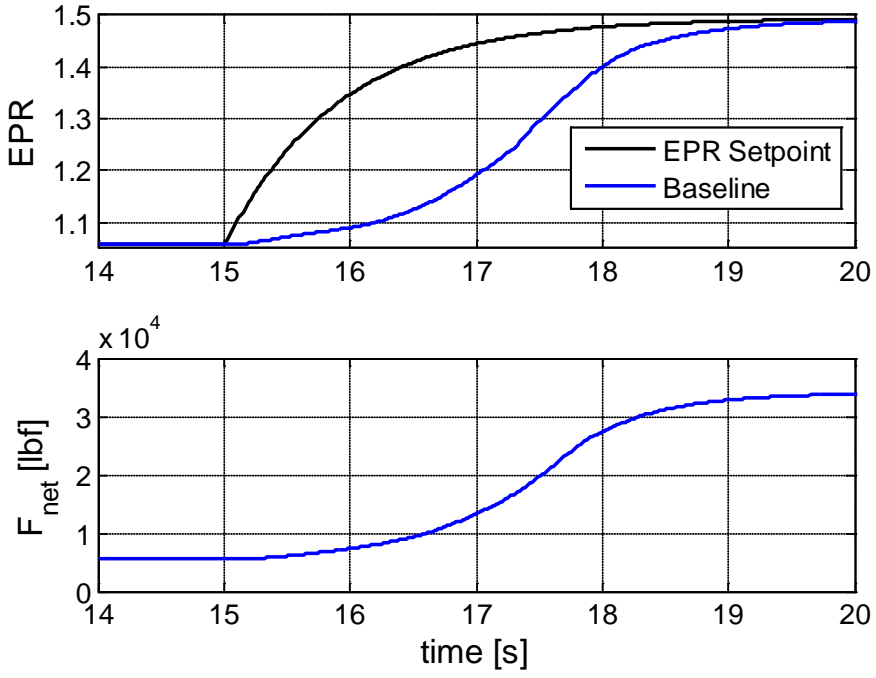

Figure 5.-EPR and thrust responses to a full throttle change at $15 \mathrm{~s}$ at SLS flight conditions with a fully deteriorated engine.

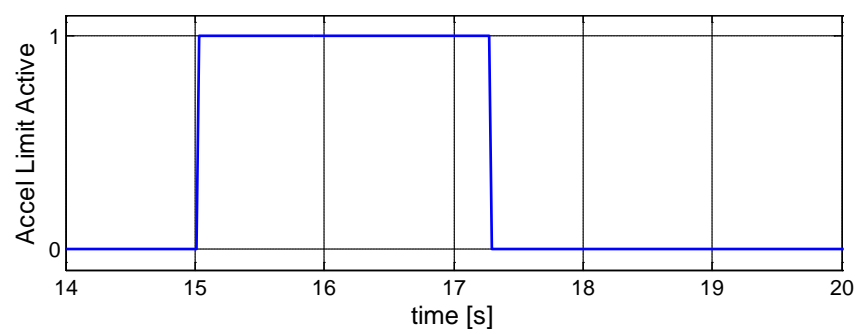

Figure 6.-Acceleration limit regulator state during a SLS fullthrottle burst at $15 \mathrm{~s}$ with a fully deteriorated engine.

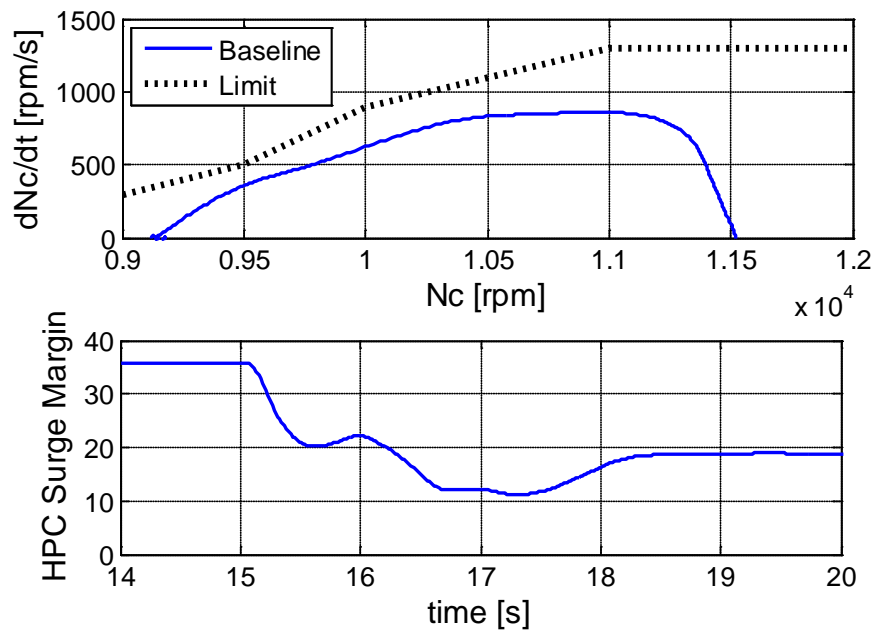

Figure 7.-Impact of the acceleration limiter during a SLS fullthrottle burst at $15 \mathrm{~s}$ for a baseline controller. 
To determine an acceptable value of $\alpha$ for a specific limit regulator, the error rate limit condition is "ignored" and only Condition 1 is necessary for activation of the CA limit regulator. Thus, to determine an appropriate value of $\alpha$, only the criterion associated with Equation (5) or Equation (7) is considered sufficient to activate that particular regulator. As an example, for the case of the acceleration limiter, various values of $\alpha$ are tested for the impact on being able to stay within the HPC surge limit. Note that "ignoring" the error rate limit condition is analogous to setting $\beta$ to infinity in Equation (6) or Equation (8). The HPC surge margin for various values of $\alpha$ with the fully deteriorated engine and the throttle command as before is plotted in Figure 8. Here all values of $\alpha$ less than 0.75 result in the CA limit regulator not being able to prevent HPC surge. Note that while the remaining surge margin with $\alpha=0.75$ is small (approximately 2 percent), it is considered sufficient as it is greater than zero. This is because the C-MAPSS40k simulation includes transient surge margin models that take into account engine deterioration, changes in compressor tip clearance, heating effects, and transient operation. In an actual engine design, the amount of remaining surge margin would need to be higher to account for engine-to-engine variation, inlet distortion effects, and modeling uncertainties Reference 9.

With the value of $\alpha$ fixed at 0.75 , the effect of error rate on the limit regulator being active is considered as $\beta$ is varied. Based on how $\beta$ is defined, the larger the value of $\beta$, the more sensitive the limiter activation will be to small deviations from

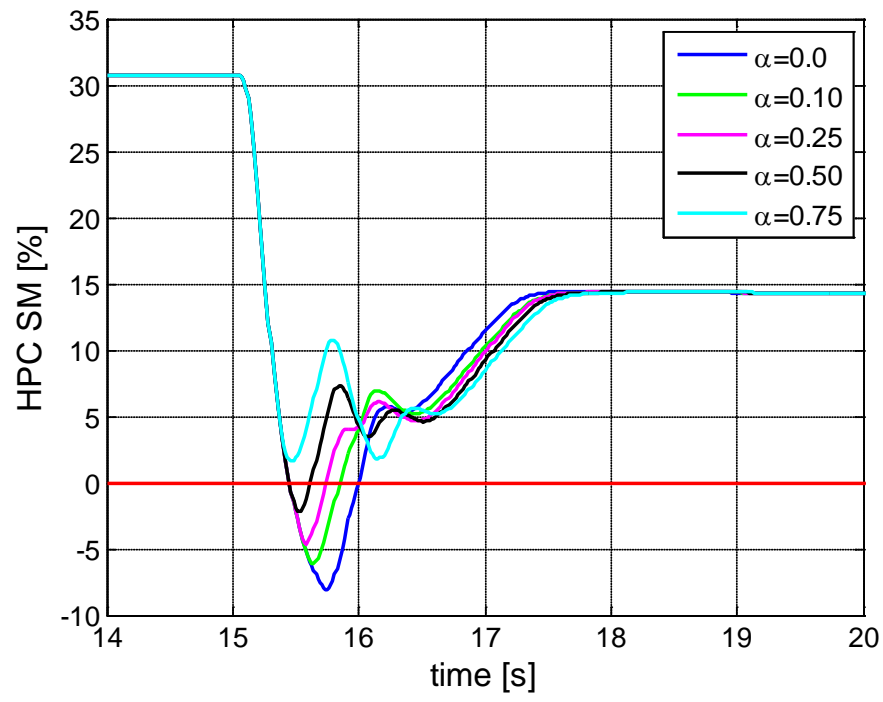

Figure 8.-HPC surge margin for various choices of $\alpha$ on the acceleration limiter ( $\beta$ fixed at infinity). The test case used here is a full-throttle burst (at $15 \mathrm{~s}$ ) at SLS conditions with a fully deteriorated engine. the limit. In Figure 9 the impact of changing $\beta$ on the HPC surge margin is shown. Note that as $\beta$ is increased the closer it follows the $\beta=\infty$ curve. The choice of $\beta=30$ produces a safe transient; increasing the value any further only serves to make the limiter too sensitive to noise or other disturbances.

Although performance can be improved by adjusting the acceleration schedule itself, doing so will increase the risk of surge under extreme conditions. The acceleration schedule is designed to ensure that adequate surge margin will be maintained under all allowable operating conditions as long as the core shaft acceleration limit is not exceeded. So the CA limit regulator provides the capability to achieve improved performance by allowing the engine to operate closer to the acceleration limit that guarantees adequate surge margin.

This process of determining the limit activation parameters $\alpha$ and $\beta$ is then repeated for each of the other engine limit regulators. This results in the choice of parameter values as shown in Table 1.

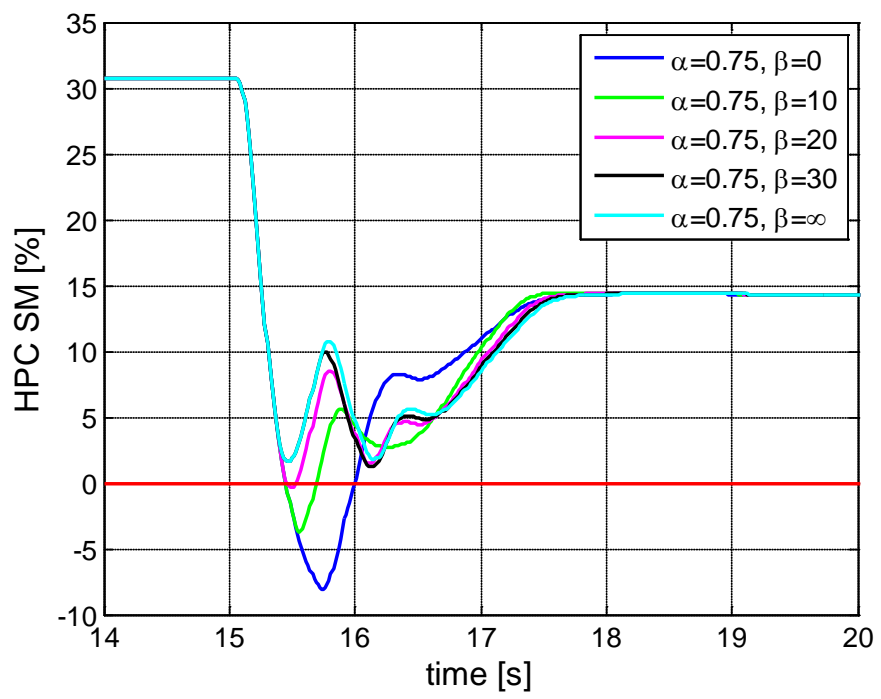

Figure 9.-HPC surge margin for various choices of $\beta$ on the acceleration limiter ( $\alpha$ fixed at 0.75). The test case used here is a full-throttle burst (at $15 \mathrm{~s}$ ) at SLS conditions with a fully deteriorated engine.

TABLE 1.-CONSTANTS CHOSEN FOR THE FIVE CONDITIONALLY ACTIVE LIMITERS IN C-MAPSS40K

\begin{tabular}{|l|c|c|}
\hline \multicolumn{1}{|c|}{ Limiter } & $\alpha$ & $\beta$ \\
\hline Accel & 0.75 & 30 \\
\hline Nf max & 0.10 & 20 \\
\hline Nc max & 0.20 & 20 \\
\hline Ps3 max & 0.20 & 20 \\
\hline Ps3 min & 0.20 & 20 \\
\hline
\end{tabular}




\section{Engine Performance With Conditionally Active Limit Regulators}

To determine the effectiveness of the conditionally active limit regulators on the engine response, three situations are evaluated: (1) a case where a transient limit regulator is necessary to ensure safe operation, (2) a case where a steadystate limit regulator is necessary to ensure safe operation, and (3) a case where a limit regulator becomes active unnecessarily during a transient.

During testing it was discovered that the C-MAPSS40k EPR setpoints are very conservative and, during normal operation, only the acceleration limiter is typically encountered. Future versions of the simulation will address this by developing a more aggressive EPR setpoint schedule in which the limiters act to bound the envelope of operation. For the purposes of this study, case 1 will evaluate the performance of the acceleration limiter while the core speed limiter will be used to evaluate both cases 2 and 3 .

To evaluate case 1 , the previous study of a full throttle burst at sea-level static conditions is examined in more detail. A step throttle change is commanded at $15 \mathrm{~s}$ to an engine with the baseline control law and one in which the conditionally active limiters are installed. The engine is fully degraded to test a worst-case scenario.

The throttle change is commanded internally as an EPR command as shown in Figure 10 for both the baseline control law and the controller utilizing CA limit regulators. The 90 percent rise time for the baseline case is $3.47 \mathrm{~s}$ compared to $2.79 \mathrm{~s}$ for the case with the CA limit regulators-a reduction of nearly 20 percent. This corresponds with the finding in Figure 11 that the baseline acceleration limit regulator is active for $2.28 \mathrm{~s}$, whereas the CA limit regulator is only active for a total of $0.54 \mathrm{~s}$ during two periods.

Examining the HPC surge margin (Fig. 12) for both cases highlights the fact that in the baseline case, the engine controller behaves in a conservative (surge margin is much greater than zero during the transient) manner. The use of the conditionally active limiters reduces this conservatism while maintaining a positive surge margin. Additionally, the core shaft acceleration versus core shaft speed is plotted in Figure 12. Again, the inherent conservatism of the baseline limiter can be seen. This conservatism is removed when the CA limiter is used, resulting in much higher accelerations, and thus faster engine response.

In addition to studying the fully deteriorated engine, the same test was conducted with a new engine. The results are nearly identical to those shown in Figures 10 to 12 with the single exception that the HPC surge margin is approximately 3 percent higher for all cases when using a new engine. Due to the similar nature of the results, the plots are not included in this paper.

Case 2 studies the behavior of the engine when a steadystate limit, such as a core shaft speed limit, is encountered. For this case, a flight condition of 10,000 ft, Mach 0.8, and
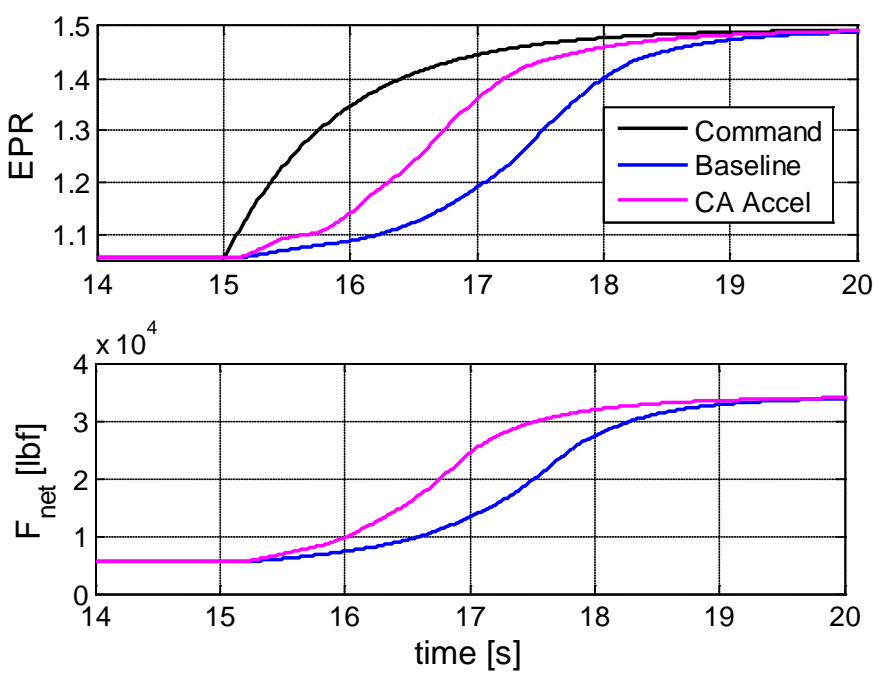

Figure 10.-EPR and thrust responses to a full throttle change at $15 \mathrm{~s}$ at SLS flight conditions with a fully deteriorated engine.

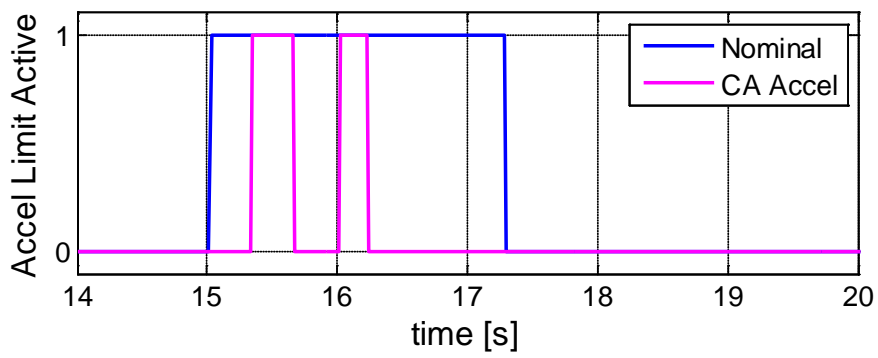

Figure 11.-Acceleration limit regulator state during a SLS fullthrottle burst at $15 \mathrm{~s}$ with a fully deteriorated engine for both baseline and CA limiters.
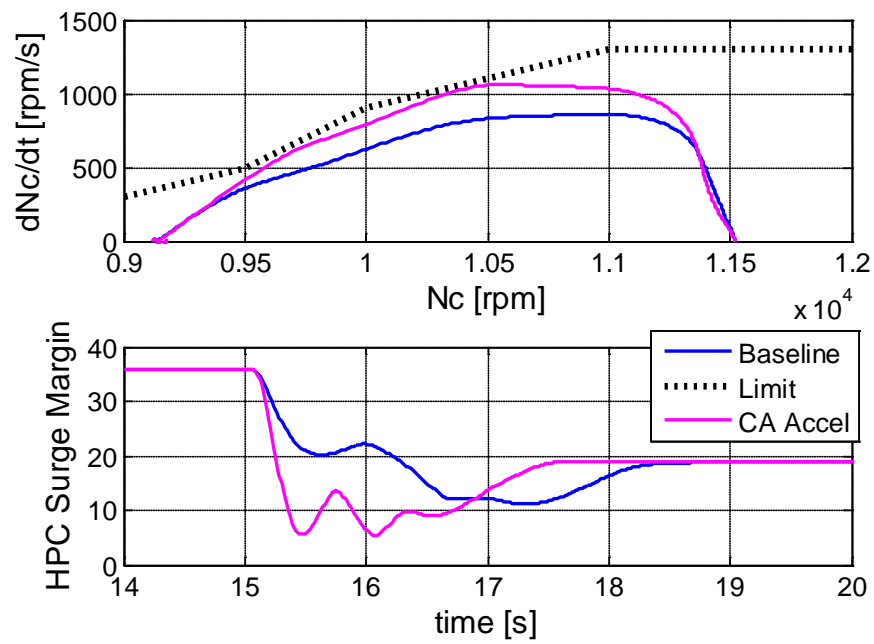

Figure 12.- Impact of the acceleration limiter during a SLS fullthrottle burst at $15 \mathrm{~s}$ for a baseline controller and a controller with CA limiters. 

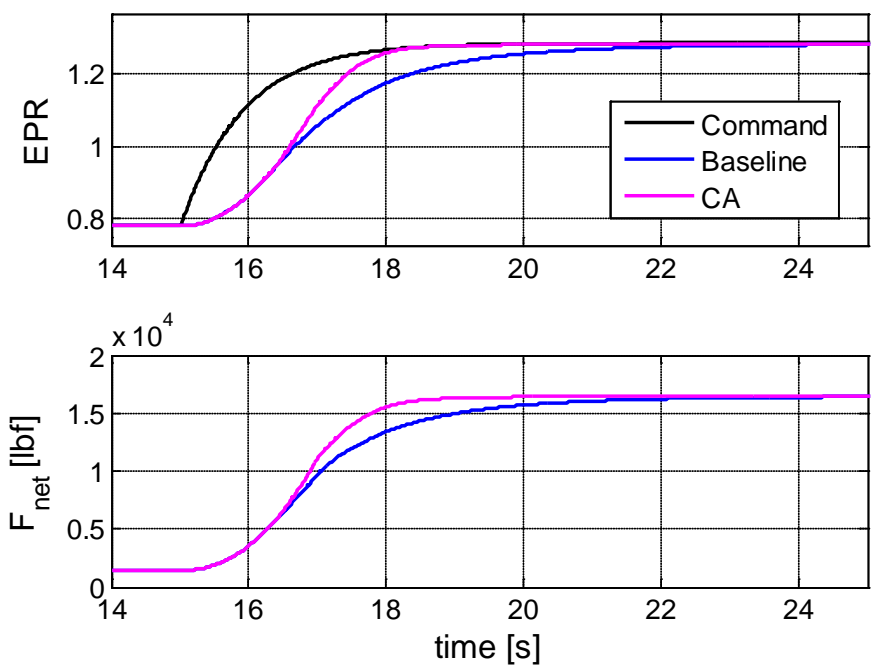

Figure 13.-EPR and net thrust generated by engine during a full throttle transient at $15 \mathrm{~s}(10,000 \mathrm{ft}$, Mach 0.8, ISA+50 R) for a baseline controller and controller with CA limiters.

ISA+50 R is used. Again, an idle to full throttle transient is executed with the baseline control system and with the conditionally active limiters. For this case, the engine is considered to be new - that is all health parameter deviations are set to zero to indicate no deterioration.

The EPR and net thrust responses with the baseline control and the CA limit regulators are shown in Figure 13. The benefit of using the CA limit regulator is apparent from the results in Figure 13. In this case, the 90 percent rise time is reduced from 5.05 to $2.68 \mathrm{~s}$. Also, it should be noted that there is a steady-state EPR error of 0.004 which cannot be seen in the plot at this scale. This error is due to the fact that the core speed limit regulator is active and preventing the EPR setpoint from being attained.

The fact that the core shaft speed hits the limit and remains there after the transient is shown in Figure 14. Shown are the core shaft speed responses as well as the core speed limit. It should be noted that the core speed limit is the same for both configurations. It can be seen that the CA limit regulator case reaches the limit much faster than the baseline case. For both cases, the core shaft speed limit is maintained and there are no oscillations.

To examine the impact of the CA limiter, the state of the $\mathrm{NC}$ max limiter and Accel limiter are plotted along with the state of the EPR setpoint controller (Fig. 15). Due to the nature of the Min-Max architecture, only one of these can be active at any given time. In the baseline case, the EPR setpoint controller drives the transient for approximately the first $1.2 \mathrm{~s}$ and then the core speed limiter takes over. Note that at this point, the core speed is only 10,860 rpm while the limit is $12,200 \mathrm{rpm}$. By comparison, with the CA limiters, the Nc max limiter does not become active until $5 \mathrm{~s}$ after the transient when the core speed is approximately $4.0 \mathrm{rpm}$ below the limit. There is some chatter in the state of $N c$ max limit regulator as the changing control action results in the error rate criteria,

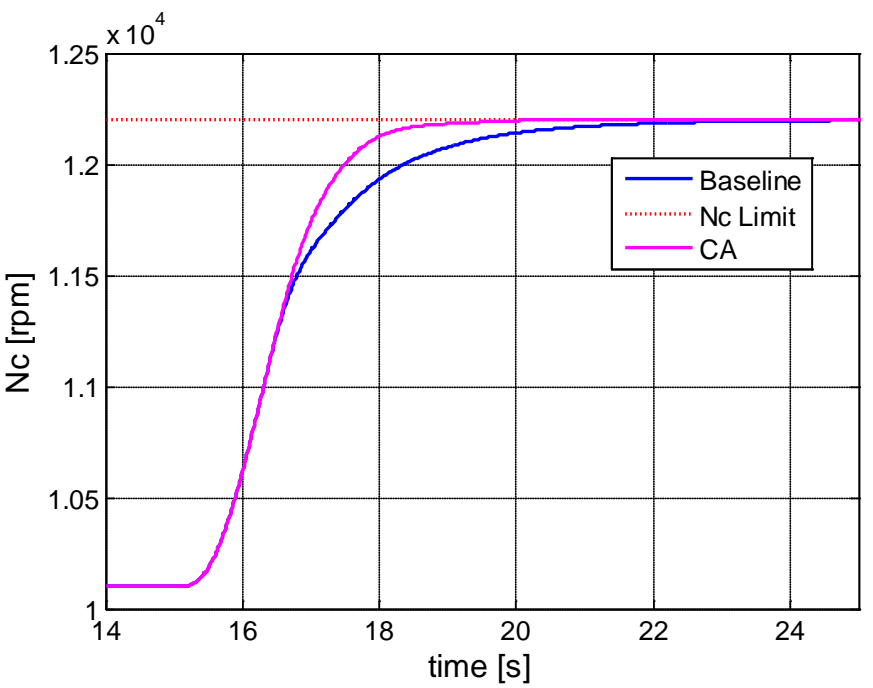

Figure 14.-Core shaft speed and limit for a full throttle burst at $15 \mathrm{~s}(10,000 \mathrm{ft}$, Mach 0.8, ISA+50 R).

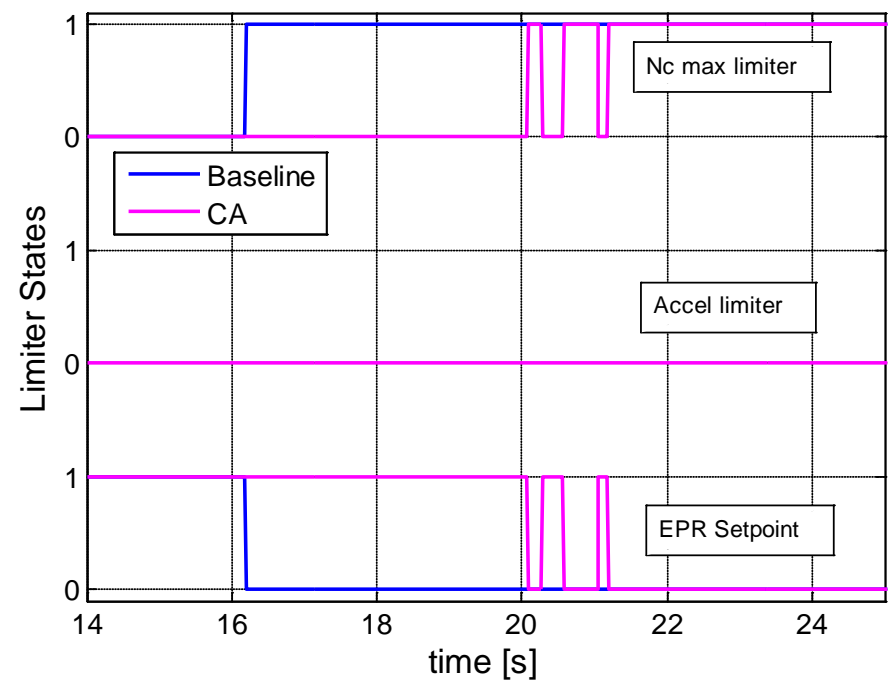

Figure 15.--State of the core shaft speed limiter, acceleration limiter, and EPR setpoint controller during a full throttle burst at $15 \mathrm{~s}(10,000 \mathrm{ft}$, Mach 0.8, ISA+50 R).

Equation (6), becoming false, then true as the EPR setpoint regulator assumes control. While there are no observed negative effects of this chatter, some hysteresis can be added to the CA logic to smooth out the control action.

Case 3 is evaluated in which a steady-state limiter is unnecessarily active for the baseline controller. This is analogous to the temperature limit prematurely limiting the response in the initial NASA study Reference 4 discussed in the introduction. Here, the test is conducted at a flight condition of $15,000 \mathrm{ft}$, Mach 0.8 , and ISA+50 R with a new engine.

The EPR and net generated thrust are shown for the baseline controller and controller with CA limit regulators in Figure 16. There is a small improvement in engine response: the 90 percent rise time decreases from 3.22 to $2.95 \mathrm{~s}$ (an 8.4 percent reduction). 

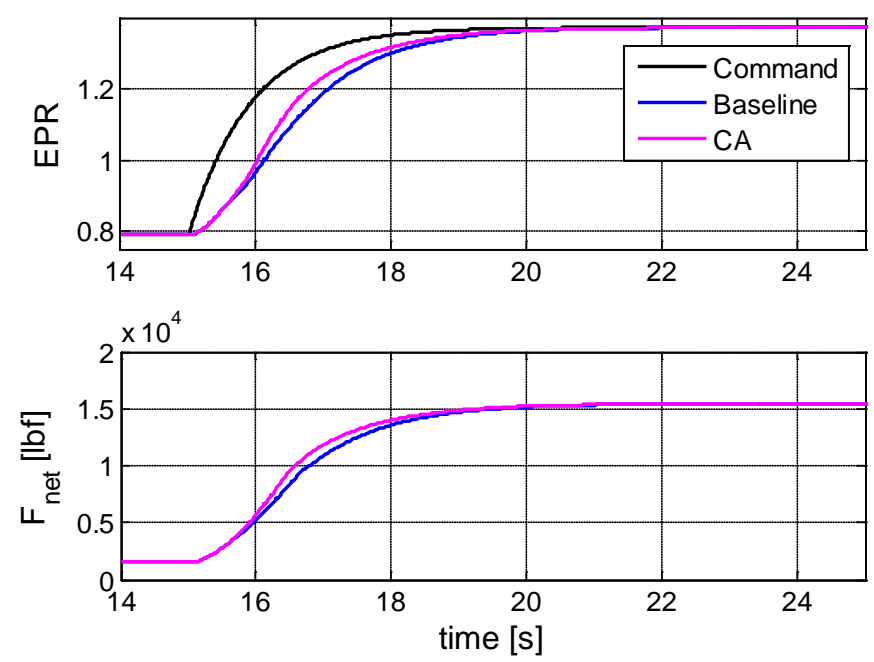

Figure 16.-EPR and net thrust generated by engine during a full throttle transient at $15 \mathrm{~s}(15,000 \mathrm{ft}$, Mach 0.8, ISA+50 R) for a baseline controller and controller with CA limiters.

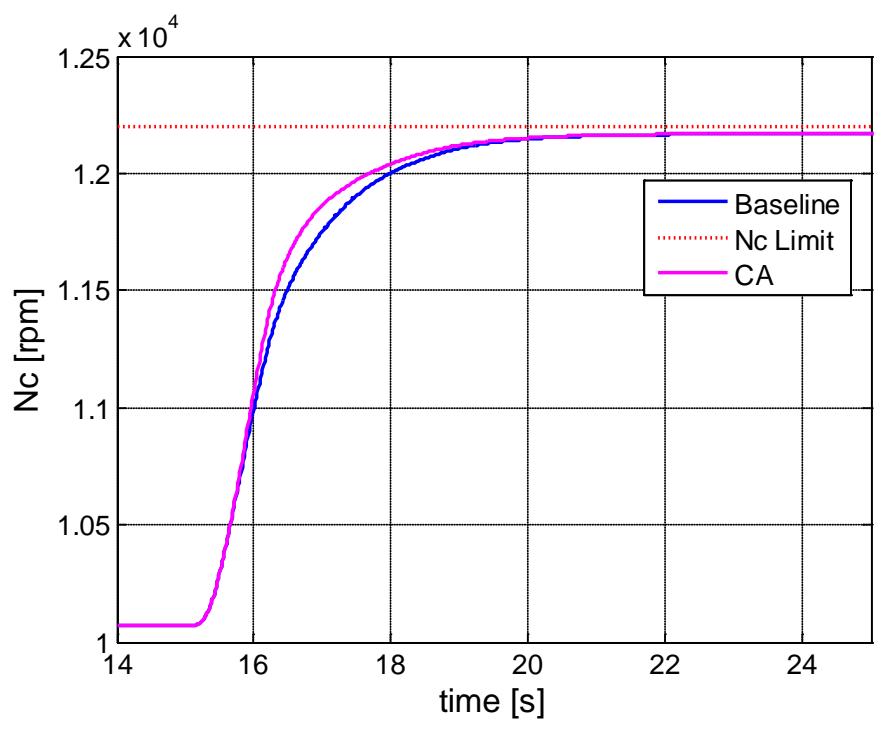

Figure 17.-Core shaft speed and limit for the baseline controller and controller with CA limiters for a full throttle burst at $15 \mathrm{~s}(15,000 \mathrm{ft}$, Mach 0.8, ISA+50 R).

The core shaft speeds for both controller configurations are plotted in Figure 17 along with the core speed limit. It is apparent that in both cases the physical limit is never encountered during the transient or at the new operating point. Thus, the core speed limit regulator has no need to become active.

Figure 18 shows the state of the Nc max limiter, Accel limiter, and the state of the EPR setpoint controller for the two controller configurations. When using the baseline controller, the Nc max limiter is indeed active (for $0.66 \mathrm{~s}$ ). When the CA limiters are used, the core speed limit regulator never becomes active. Additionally, the amount of time spent on the acceleration limiter is greatly reduced when using the CA limiters ( $0.19 \mathrm{~s}$ compared to $0.53 \mathrm{~s}$ for the baseline).

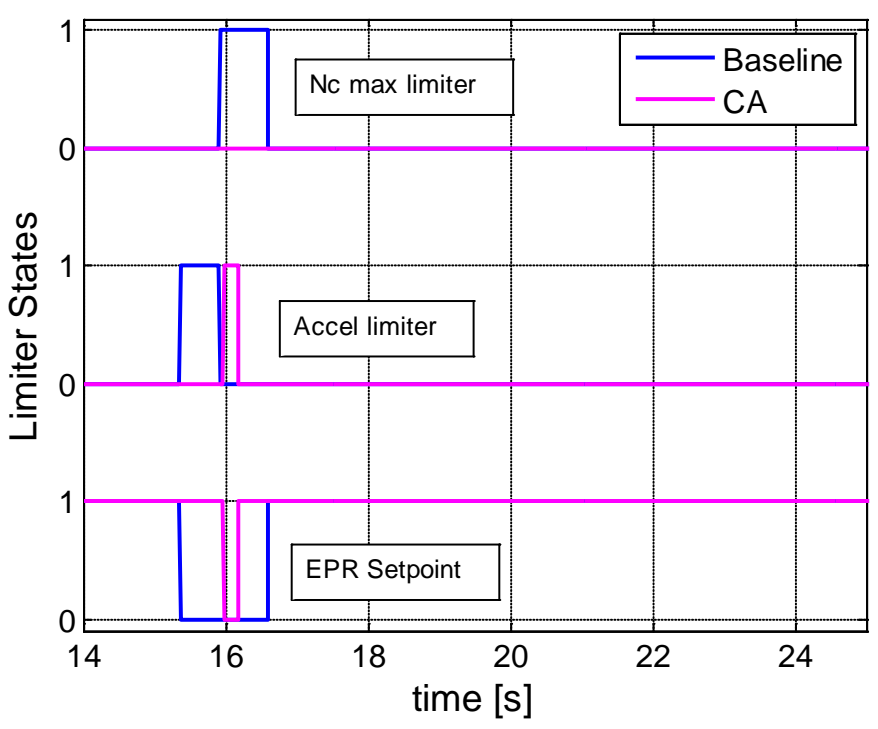

Figure 18.-State of the core shaft speed limiter, acceleration limiter, and EPR setpoint controller during a full throttle burst at $15 \mathrm{~s}(15,000 \mathrm{ft}$, Mach 0.8, ISA+50 R).

In the three cases evaluated, the engine controller using CA limit regulators has been shown to result in faster engine response while ensuring engine safety. The improved performance is attained by eliminating unnecessary limit regulator activations and by utilizing more of the available safety margins. These cases were used to demonstrate the benefits of using CA limit regulators. While no negative impacts of the CA limit regulator were observed for these cases, a complete validation of the CA limit regulator architecture would be required just as was done for the baseline control design.

\section{Conclusions}

The concept of using CA limit regulators in the Min-Max architecture of typical engine control laws was introduced. The CA architecture in the Min-Max scheme only activates the limit regulators when the operating point is within a certain bound of the limit and approaching the limit at a faster than prescribed rate. This is unlike the typical approach where the limit regulators can become inadvertently activated, thereby limiting the system response time. The selection of the bounds for the CA limit regulator architecture was demonstrated using a publicly available detailed dynamic simulation of a commercial aircraft engine. The results presented in this paper showed that by properly choosing the parameters that activate the CA limit regulators, the engine response can be improved while preserving all necessary safety limits. It should be noted that the CA limiters require tuning and need to be fully evaluated under realistic situations (such as sensor noise and engine deterioration). While the bounds for the CA limit regulators were empirically determined in this study, research needs to be done to develop a more rigorous analytical approach to provide guidelines for the selection of these bounds. 


\section{References}

1. Csank, J., May, R.D., Litt, J.S., and Guo, T.-H., "Control Design for a Generic Commercial Aircraft Engine," AIAA-2010-6629, 46th AIAA Joint Propulsion Conference \& Exhibit, Nashville, TN, July 25-28, 2010.

2. Jaw, L., and Mattingly, J.D., Aircraft Engine Controls: Design, System Analysis, and Health Monitoring, American Institute of Aeronautics and Astronautics, Inc., Virginia, 2009.

3. Burcham, F.W., Jr., Fullerton, C.G., and Maine, T.A., "Manual Manipulation of Engine Throttles for Emergency Flight Control,” NASA/TM-2004-212045, January 2004.

4. Litt, J.S., Frederick, D.K., and Guo, T.-H, "The Case for Intelligent Propulsion Control for Fast Engine Response," AIAA-2009-1876, AIAA Infotech@Aerospace Conference, Seattle WA, June 6-9, 2009.

5. Richter, Hanz, and Litt, Jonathan S., “A Novel Controller for Gas Turbine Engines with Aggressive Limit Management,” AIAA-2011-5857, 47th AIAA/ASME/ SAE/ASEE Joint Propulsion Conference \& Exhibit, July 31-August 3, 2011, San Diego, CA.
6. Weiss, A., Kolmanovsky, I., Merrill, W., "Incorporating Risk into Control Design for Emergency Operation of Turbo-Fan Engines,” AIAA-2011-1591, Infotech @ Aerospace 2011, St. Louis, MO, March, 2011.

7. May, R.D., Csank, J., Lavelle, T.M., Litt, J.S., and Guo, T.H., "A High-Fidelity Simulation of a Generic Commercial Aircraft Engine and Controller," AIAA2010-6630, 46th AIAA Joint Propulsion Conference \& Exhibit, Nashville, TN, July, 2010.

8. Spang III, A.H., and Brown, H., "Control of Jet Engines," Control Engineering Practice, 8 March 1999, pp. 10431059.

9. Walsh, P.P., Fletcher, P., "Gas Turbine Performance," 2nd Edition, ASME Press, Blackwell Publishing, New Jersey, 2004. 



\begin{tabular}{|c|c|c|}
\hline \multicolumn{2}{|c|}{ REPORT DOCUMENTATION PAGE } & $\begin{array}{l}\text { Form Approved } \\
\text { OMB No. 0704-0188 }\end{array}$ \\
\hline \multicolumn{3}{|c|}{$\begin{array}{l}\text { The public reporting burden for this collection of information is estimated to average } 1 \text { hour per response, including the time for reviewing instructions, searching existing data sources, gathering and maintaining the } \\
\text { data needed, and completing and reviewing the collection of information. Send comments regarding this burden estimate or any other aspect of this collection of information, including suggestions for reducing this } \\
\text { burden, to Department of Defense, Washington Headquarters Services, Directorate for Information Operations and Reports (0704-018), } 1215 \text { Jefferson Davis Highway, Sulite } 1204 \text {, Arlington, VA } 22202-4302 \text {. } \\
\text { Respondents should be aware that notwithstanding any other provision of law, no person shall be subject to any penalty for failing to comply with a collection of information if it does not display a currently valid OMB } \\
\text { control number. } \\
\text { PLEASE DO NOT RETURN YOUR FORM TO THE ABOVE ADDRESS. }\end{array}$} \\
\hline $\begin{array}{l}\text { 1. REPORT DATE (DD-MM-YYYY) } \\
01-12-2012\end{array}$ & $\begin{array}{l}\text { 2. REPORT TYPE } \\
\text { Technical Memorandum }\end{array}$ & 3. DATES COVERED (From - To) \\
\hline \multirow{3}{*}{\multicolumn{2}{|c|}{$\begin{array}{l}\text { 4. TITLE AND SUBTITLE } \\
\text { Reducing Conservatism in Aircraft Engine Response Using Conditionally Active Min-Max } \\
\text { Limit Regulators }\end{array}$}} & 5a. CONTRACT NUMBER \\
\hline & & 5b. GRANT NUMBER \\
\hline & & 5c. PROGRAM ELEMENT NUMBER \\
\hline \multirow{3}{*}{\multicolumn{2}{|c|}{$\begin{array}{l}\text { 6. AUTHOR(S) } \\
\text { May, Ryan, D.; Garg, Sanjay }\end{array}$}} & 5d. PROJECT NUMBER \\
\hline & & 5e. TASK NUMBER \\
\hline & & $\begin{array}{l}\text { 5f. WORK UNIT NUMBER } \\
\text { WBS 284848.02.06.03.02 }\end{array}$ \\
\hline \multicolumn{2}{|c|}{$\begin{array}{l}\text { 7. PERFORMING ORGANIZATION NAME(S) AND ADDRESS(ES) } \\
\text { National Aeronautics and Space Administration } \\
\text { John H. Glenn Research Center at Lewis Field } \\
\text { Cleveland, Ohio 44135-3191 }\end{array}$} & $\begin{array}{l}\text { 8. PERFORMING ORGANIZATION } \\
\text { REPORT NUMBER } \\
\text { E-18550 }\end{array}$ \\
\hline \multirow{2}{*}{\multicolumn{2}{|c|}{$\begin{array}{l}\text { 9. SPONSORING/MONITORING AGENCY NAME(S) AND ADDRESS(ES) } \\
\text { National Aeronautics and Space Administration } \\
\text { Washington, DC 20546-0001 }\end{array}$}} & $\begin{array}{l}\text { 10. SPONSORING/MONITOR'S } \\
\text { ACRONYM(S) } \\
\text { NASA }\end{array}$ \\
\hline & & $\begin{array}{l}\text { 11. SPONSORING/MONITORING } \\
\text { REPORT NUMBER } \\
\text { NASA/TM-2012-217814 }\end{array}$ \\
\hline \multicolumn{3}{|c|}{$\begin{array}{l}\text { 12. DISTRIBUTIONIAVAILABILITY STATEMENT } \\
\text { Unclassified-Unlimited } \\
\text { Subject Category: } 07 \\
\text { Available electronically at http://www.sti.nasa.gov } \\
\text { This publication is available from the NASA Center for AeroSpace Information, 443-757-5802 }\end{array}$} \\
\hline
\end{tabular}

\section{SUPPLEMENTARY NOTES}

\section{ABSTRACT}

Current aircraft engine control logic uses a Min-Max control selection structure to prevent the engine from exceeding any safety or operational limits during transients due to throttle commands. This structure is inherently conservative and produces transient responses that are slower than necessary. In order to utilize the existing safety margins more effectively, a modification to this architecture is proposed, referred to as a Conditionally Active (CA) limit regulator. This concept uses the existing Min-Max architecture with the modification that limit regulators are active only when the operating point is close to a particular limit. This paper explores the use of CA limit regulators using a publicly available commercial aircraft engine simulation. The improvement in thrust response while maintaining all necessary safety limits is demonstrated in a number of cases.

\section{SUBJECT TERMS}

Commercial aircraft; Propulsion system

\begin{tabular}{|c|c|c|c|c|c|}
\hline \multicolumn{3}{|c|}{ 16. SECURITY CLASSIFICATION OF: } & \multirow{2}{*}{$\begin{array}{l}\text { 17. LIMITATION OF } \\
\text { ABSTRACT } \\
\text { UU }\end{array}$} & \multirow{2}{*}{$\begin{array}{l}\text { 18. NUMBER } \\
\text { OF } \\
\text { PAGES } \\
18\end{array}$} & \multirow{2}{*}{$\begin{array}{l}\text { 19a. NAME OF RESPONSIBLE PERSON } \\
\text { STI Help Desk (email:help@sti.nasa.gov) } \\
\text { 19b. TELEPHONE NUMBER (include area code) } \\
\text { 443-757-5802 }\end{array}$} \\
\hline $\begin{array}{l}\text { a. REPORT } \\
\mathrm{U}\end{array}$ & $\begin{array}{l}\text { b. ABSTRACT } \\
\text { U }\end{array}$ & $\begin{array}{l}\text { c. THIS } \\
\text { PAGE } \\
\text { U }\end{array}$ & & & \\
\hline
\end{tabular}



